\title{
A política estadunidense de desgermanização do sistema de transporte aéreo brasileiro: o caso da Condor
}

The American Policy for the De-germanization of Brazilian Air Transport System: the case of the Condor Company

TÂNIA QUINTANEIRO*

Rev. Bras. Polít. Int. 52 (1): 110-132 [2009]

\section{Introdução}

Desde meados da década de 1930, o Departamento de Estado norteamericano vinha criando agências para promover, além-mar, a produção industrial estadunidense. Nelas eram alocados funcionários qualificados em tarefas de inteligência com o fim de monitorar e captar mercados. Alguns desses braços se estenderam na direção da América Latina, um espaço promissor à espera de investidores, o qual, no final da década, acabou por se tornar inalcançável para os europeus. A oportunidade de expandir-se, vislumbrada na Primeira Guerra, foi aproveitada, portanto, na Segunda. ${ }^{1}$

O esforço para penetrar no dinâmico mercado de aviação e de transporte aéreo da região amparou-se em pressóes para estabelecer alianças com alguns governos latino-americanos. Ajustou-se ao argumento de que a aviação comercial era, no contexto da guerra, um meio para espionagem e agressão ao continente. Isso serviu também de justificativa para o uso de mecanismos de controle, como as eficazes Listas Negras. ${ }^{2}$ Por meio delas, bloqueava-se capital dos países do Eixo, assim como atividade de técnicos e acionistas, mesmo os naturalizados ou residentes, ou qualquer um que possuísse ligaçôes, reais ou supostas, com o Eixo. Isso obrigou fornecedores, compradores e seguradoras a cortar relações comerciais com os bloqueados. Para sobreviver no mercado, a opção era negociar exclusivamente com os Aliados. A lenta asfixia e a sujeição de tais empresas foram mantidas de forma rígida, principalmente pelos Estados Unidos, que tinham maior capacidade

\footnotetext{
* Professora do Departamento de Sociologia e Antropologia da Universidade Federal de Minas Gerais UFMG (taniaq@terra.com.br).

1 A pesquisa de fontes realizou-se nos National Archives and Records Administration (NARA), em Maryland, com recursos da FAPEMIG.

2 Por esse nome eram conhecidas, no Brasil, a Proclaimed List of Blocked Nationals e a British Statutory List. Ver Quintaneiro, 2006.
} 
de pressão, aparato organizado e apoio bem concertado de suas embaixadas e de agentes especiais ligados a vários órgãos do Estado.

A empresa de transporte aéreo Condor, embora obedecesse à legislação brasileira, era subsidiária da Lufthansa e estava equipada com aeronaves alemãs. Nesse artigo, será examinada e avaliada a atuação conjunta do Estado e do capital privado norte-americanos no sentido de forçar o governo Vargas a nacionalizar a Condor e substituir seu equipamento, funcionários e acionistas por outros 'confiáveis', cedendo lugar a indústrias aeronáuticas dos Estados Unidos e eventualmente a empresas aéreas desse país. Apesar das tentativas do governo brasileiro de confrontar a pressão e proteger os trabalhadores alemães e naturalizados, a pressão favoreceu o projeto político e comercial estadunidense, iniciando a prolongada consolidação dos laços econômicos entre os dois países. Nesse processo, o discurso ideológico, que destacava a superioridade tecnológica dos artefatos aeronáuticos norte-americanos e a necessidade de reforçar a solidariedade entre os países aliados, desempenhou um papel da maior importância.

\section{Os alemães no transporte aéreo sul-americano}

A presença de imigrantes germânicos já era conspícua, na América do Sul antes do início da Segunda Guerra. Aos poucos, eles haviam fincado raízes e prosperado, e alguns se tornaram parte das elites socioeconômicas e políticas, o que teve ressonâncias inesperadas quando passaram a ser vistos pelo Departamento de Estado como uma espécie de quinta coluna a ser neutralizada. Geralmente organizados em colônias, evidenciavam forte coesão social e mantinham laços com sua terra natal, sua identidade e cultura. $\mathrm{O}$ caminho do comércio, trilhado por muitos deles, complementava a atividade agrícola na qual se ocupava a maioria. Essas comunidades foram a plataforma para que bem treinados representantes comerciais, peritos na detecção de necessidades e preferências de potenciais consumidores, introduzissem hábitos de consumo, práticas contábeis e produtos alemães, e contribuíssem para disseminar uma confiança quase inabalável na qualidade dessa indústria. $O$ papel do agente comercial foi estratégico na adaptação da produção às idiossincrasias locais e na conquista, ao longo dos anos 30, de fatia importante dos mercados sul-americanos. Em suas tentativas de penetração, o capital estadunidense teve de levar em conta esse fator.

As máquinas e os sistemas aeronáuticos germânicos estavam entre os mais avançados quando foram adquiridos por algumas das primeiras linhas aéreas comerciais sul-americanas. Dado o elevado custo desses artefatos e o conhecimento que sua operacionalização exigia, feito o primeiro investimento em sua aquisição, o cliente tendia a solicitar treinamento, peças e inovações tecnológicas da mesma fonte. Os alemães usavam o sistema de pool, e, com ele, "ganharam o controle sobre as linhas aéreas domésticas", garantindo peças e manutenção aos aviōes que, em caso de acidentes ou ocorrências, eram transferidos de uma linha para outra 
para máxima eficiência. ${ }^{3}$ Quando os Estados Unidos se sentiram politicamente fortalecidos, trataram de extirpar, das empresas de transporte aéreo da América, proprietários, dirigentes, acionistas, pilotos e técnicos do Eixo e pessoas a eles relacionadas, apontados como ameaça à segurança do continente. Ao mesmo tempo, cuidariam de substituir capitais, equipamentos e métodos de operação, para aumentar as possibilidades de captar mercados já formados e com possibilidades de expansão.

Subsidiária da Reconstruction Finance Corporation (RFC), a Defense Supplies Corporation (DSC) era uma dessas novas agências do governo dos Estados Unidos. Dedicava-se a administrar a escassez de produtos nas frentes de batalha, e a oferecer assistência financeira e técnica e suprimentos às linhas aéreas estadunidenses que atendiam aos países da América. Seus experts criavam bancos de dados sobre aeronaves, milhas voadas, número de passageiros, rotas, métodos e finanças das companhias, articulavam planos e buscavam aliados nas elites políticas, empresariais e militares locais. Os projetos eram apresentados ao governo norteamericano, para financiamento e subsídios, e aos interesses privados. As seçóes econômicas das embaixadas atuavam como órgãos executivos nas negociações com as autoridades nacionais, considerando,

primeiro, a necessidade de, por todos os meios possíveis, proteger, manter e desenvolver os serviços internacionais dos Estados Unidos; segundo, a probabilidade de que a maioria das outras repúblicas americanas deseje ter suas respectivas linhas domésticas e alimentadoras assumidas por companhias genuinamente nacionais e, terceiro, a possibilidade de cooperação com tais governos na criação de companhias nacionais por meio de créditos para a compra de aeronaves e equipamentos e talvez também para as operações iniciais. Nesse caso também se considerava a participação, como acionistas minoritárias em tais companhias domésticas, de transportadoras dos Estados Unidos - sejam as operadoras atuais dos serviços internacionais ou outros interesses da aviação. ${ }^{4}$

O embaixador dos Estados Unidos no Brasil, Jefferson Caffery, foi instruído a tratar de tais temas reservadamente com o ministro das Relaçôes Exteriores do Brasil, Oswaldo Aranha, e outras autoridades, a enfatizar as vantagens, para o Brasil, de ter a propriedade e administração "das companhias aéreas do país agora pertencentes a europeus, tanto quanto a liderança e prestígio que vai obter no campo da aviação", acenando com uma qualidade igual ou superior à existente. Confidencialmente, fora informado da disponibilidade de fundos nãoreembolsáveis para o alcance de alguns desses pontos.

3 Summary Report on Air Activity in Brazil and South America, 1941, p.5.

4 United States State Department. 30/7/1940. 


\section{O quadro do transporte aéreo brasileiro}

As previsōes de um aumento no fluxo entre as Américas trouxeram ao Rio de Janeiro, em outubro de 41, uma comissão de congressistas estadunidenses para investigar as condições das aeronaves e aeroportos, o treinamento e competência de pilotos e tripulações, restrições legais a pessoal de operação, e a suficiência de serviços de rádio, meteorologia e auxílio à navegação. Ela constatou que a pequena frota da Navegação Aérea Brasileira (NAB) era estadunidense, mas sua operação irregular e em condiçõos pouco seguras. A substituição dos monomotores alemães da Viação Aérea São Paulo (Vasp) era urgente, sob pena de fechamento da companhia, situação similar à da Viação Aérea Rio-Grandense (Varig). Muitos dos pilotos de ambas descendiam de alemães e obtinham "notável sucesso em condições consideradas inseguras nos Estados Unidos". Praticamente inexistiam meios de treinamento em aviōes multimotores ou em navegação e voo por instrumentos; militares e civis vinham sendo encaminhados em número crescente aos Estados Unidos como aprendizes. ${ }^{5}$

Diagnósticos feitos por consultores das agências e da Embaixada do Estados Unidos no Brasil foram traçando um quadro pormenorizado das empresas de transporte aéreo doméstico. Com base neles, um plano conjunto da Divisão de Aviação das Repúblicas Americanas do Departamento de Estado, dos Departamentos de Guerra, Marinha e Aeronáutica Civil e da Coordenadoria de Relações Comerciais e Culturais entre as Repúblicas Americanas foi apresentado ao assistente do secretário de Estado, ao consultor de Relações Políticas da Divisão das Repúblicas Americanas (Lawrence Duggan) e aos chefes das divisões das Repúblicas Americanas e de Comunicaçōes Internacionais. Também seriam distribuídas cópias à RFC, à Pan American World Airways (Pan Am) e ao Civil Aeronautics Board. O objetivo da proposta era "substituir não apenas equipamento alemão, mas também, tanto quanto possível, pessoal, propriedade e crédito, por equipamento, pessoal técnico, gerência, crédito e propriedade confiável de origem hemisférica". Tal mudança era inatingível sem a reposição dos operadores. E era "desejável preservar os interesses das operaçôes internacionais dos Estados Unidos" e seu controle sobre as redes locais, com exceção dos casos em que isso interferisse com o objetivo de desgermanização. ${ }^{6}$ Roosevelt autorizaria a liberação de aeronaves. O custo seria coberto com a abertura, na América, do mercado de bens e de serviços de administração, consultoria e planejamento, financiamento, sistemas de voo, técnicos, treinamento e atualização. Após importantes progressos na Colômbia, no Equador $^{7}$ e na Bolívia - a qual exibia pujante atuação alemã no transporte aéreo,

5 Committee of the House of Representatives. 16/10/1941.

6 Burden, W. 14/8/1941.

7 Os alvos foram a Sociedad Colombo-Alemana de Transportes Aéreos, o Servicio Aéreo Colombiano e a Sociedad Ecuatoriana de Transportes Aéreos. 
tendo sido usada como campo de provas para testar a eficiência da intervenção que se daria no Brasil -, o Departamento de Estado começou a exigir de Getúlio Vargas o cumprimento das legislações interamericana e nacional, que proibiam a contratação de pilotos de países do Eixo, mesmo naturalizados.

O Brasil constitui um arquétipo da participação alemã no transporte aéreo doméstico, como mostram a Serviços Aéreos Condor, ${ }^{8}$ a Varig e a Vasp. Elas mantinham vínculos exclusivos com os sistemas aeronáuticos da Alemanha e exibiam uma extensa lista de sobrenomes dessa origem entre acionistas e funcionários. A rede internacional era operada pela $\operatorname{Pan} \mathrm{Am}$ - que mantinha uma subsidiária doméstica, a Panair do Brasil, pilotada por brasileiros desde 1938 - e pela Linee Aeree Transcontinentali Italiane (LATI), expulsa em dezembro de 1941.9 A Condor tornou-se, então, o principal alvo da "desgermanização". Varig e Vasp também estiveram na mira. ${ }^{10}$ A Federal Loan Agency (FLA) estava disposta a oferecer financiamento para a fundação de companhias brasileiras ou brasileiroestadunidenses (com ou sem participação estatal) e subsídios para cobrir perdas operacionais em rotas não-viáveis. Seus peritos buscavam as vias mais promissoras para captar suporte político, bombardear as autoridades com competente propaganda e pressionar sem descanso, não lhes deixando alternativa que não a de negociar para, por fim, asfixiar os investimentos alemães. A implementação dessa política foi dificultada pelo amparo de Vargas aos imigrantes, que se atenua à medida que aumenta o poder dos Estados Unidos no cenário internacional. Contudo, não foi fácil conciliar certos propósitos do Departamento de Estado com alguns de seus objetivos estratégicos e geopolíticos, como o de apoiar o fortalecimento do Estado brasileiro e incentivar sua inserção no setor privado aéreo.

\section{A Condor e a política de segurança estadunidense}

O processo de controle e reorganização da Condor foi exemplar, tendo durado pouco mais de um ano. Ela possuía 25 aeronaves alemãs quando o comandante Cândido Muricy Filho tornou-se interventor. Era sólida, embora atuasse com equipamentos defasados. Atendia pequenas cidades como Carolina, Marabá, S. Benedito, Saboeiro, Jaícos, Floriano, Caxias, Picos, Loreto, Santo Antonio das Balsas, Grajaú, Pedreiras, Porto Velho, Labrea, Tabatinga, Rio Branco e Xapuri. A ligação por hidroplano Corumbá-Porto Velho estava inoperante, mas a empresa pedia a renovação do serviço, a extensão a novas localidades e o aumento de sua periodicidade no norte e no nordeste. O Departamento de Estado temia que ela

\footnotetext{
8 A Condor conectava o Rio a Buenos Aires, onde pousava a Condor chilena. Em janeiro de 1940, duas emendas à Constituição exigiram que fossem brasileiros seus procuradores e controle acionário.

9 Ver Quintaneiro, 2007.

10 Em 1940, em milhares de milhas, a Panair voara 1.250, a Condor 1.300, a Vasp 480 e a Varig 295, Burden, W. 14-8-1941.
} 
se aproximasse às fronteiras ou interligasse países da América, como no trajeto Corumbá-Iquitos, pedido em agosto de 40 e reiterado em abril de $41 .{ }^{11}$ Ao saber de sua pretensão de operar um trecho para o Oiapoque, Caffery informou estar "tomando as medidas apropriadas" - o que significava negociar com as autoridades simpáticas para que negassem autorização, ${ }^{12}$ mas pouca ajuda esperava do ministro da Aeronáutica, Salgado Filho, dito "favorável à causa alemã". A densa malha da empresa aérea fez com que mesmo a produção cinematográfica estadunidense, estratégica para a propaganda, não tivesse outro meio para alcançar o interior do Ceará e do Piauí que não em suas asas, ${ }^{13}$ o que foi negado pelo Embaixador dos Estados Unidos. O relações públicas da Condor, que já presenteara Aranha com uma viagem ao Chile, colocou uma aeronave à disposição de Salgado Filho, que cogitou em enchê-la com acompanhantes para uma viagem ao Nordeste. Ao se interar da proposta, a embaixada fez outra oferta, que foi aceita, enquanto os "amigos seguiram no avião militar". ${ }^{14}$

Com o avanço consistente da desgermanização na Bolívia, a embaixada anunciou recursos e pessoal para iniciar, no Brasil, ação similar. Mas sua eficácia dependia do empenho de Vargas que, além de não ser adepto incondicional da política de segurança dos Estados Unidos no continente, parecia pouco "ansioso de fazer tal movimento voluntariamente, como no caso da Bolívia". ${ }^{15}$ Consultores norte-americanos começaram a agir. Sugeriram instalar observadores brasileiros nos voos para dificultar a espionagem e impor penalidades por atrasos inexplicáveis ou comportamentos suspeitos, ${ }^{16}$ e discutiram o efeito de medidas como expropriação, pressōes, ações indiretas, restrição à venda de combustível controlado pelos aliados, oferta de serviços equivalentes ou algo de valor para Vargas, interessado em montar uma siderúrgica e modernizar o Exército. A centralidade da política de desgermanização da aviação para os Estados Unidos, premidos tanto pelas exigências da guerra quanto pelas internas, aconselhava a ampliação das concessôes, mas para tentar acelerar decisōes brasileiras usouse como pretexto a impossibilidade de atender com presteza aos pedidos de suprimentos. Acreditava-se que seria mais fácil convencer Vargas a nacionalizar a Condor quando esta sofresse privaçōes materiais, "especialmente se equipamento completamente novo for obtido em termos excepcionalmente razoáveis". ${ }^{17}$ As agências norte-americanas tiveram também de se harmonizar com os interesses da Pan Am, "o instrumento da política de aviação dos Estados Unidos no Brasil,

11 TAX. 23/4/1941.

12 Caffery, J. 16/10/1941.

13 Donnelly, W. 31/10/1941.

14 Caffery, J. 5 e 6/12/1941.

15 Burden, W. 14/8/1941.

16 E. O'S. $12 / 8 / 1941$.

$1727 / 3 / 1941$. 
e a única companhia norte-americana preparada para inaugurar imediatamente serviços transatlânticos entre o Brasil e a Europa". ${ }^{18}$

Os três principais planos norte-americanos - o Brazilian National Air Transportation, o da FLA e o da Pan Am - tinham pontos em comum. Propunham comprar as peças alemãs em estoque e aeronaves obsoletas para alocá-las em pequenas companhias nos Estados Unidos, fora do alcance das empresas brasileiras que, sem outra saída, teriam de apelar ao fornecimento estadunidense. Sugeriam investir na NAB, uma companhia "limpa", do agrado de Vargas, para que duplicasse suas rotas com novas máquinas e, assim, superar a Condor que, em crise de escassez de equipamentos, vinha, segundo Aranha, contrabandeando motores via Buenos Aires em navios espanhois. ${ }^{19}$ A FLA disponibilizaria empréstimos a fundo perdido, e o Office of Production Management, suprimentos para as companhias comerciais à míngua. Aventou-se a penetração, na Condor, do tipo quinta-coluna, de estadunidenses qualificados, contratados para instruir os brasileiros no uso do equipamento e na administração, até que o material fosse pago ou que parecesse desejável remover os infiltrados. O treino com segurança em um novo sistema era lento e indispensável, prolongando o prazo de adaptação. Não iria um acidente pôr tudo a perder, manchando o prestígio que os Estados Unidos tratavam de construir com esforço. Apesar do diagnóstico da DSC de que os padrões técnicos das empresas brasileiras eram extremamente baixos, havia um componente cultural a ser arrostado: a prática de manejo e a confiança no sistema e produtos alemães, visivelmente consolidadas no Brasil.

Em fevereiro de 1941, a Pan Am havia submetido, ao governo dos Estados Unidos, um plano: maior redução no fornecimento de combustível à Condor e eventualmente o corte total, e a compra de suas propriedades físicas pela Panair. Esta podia renovar sua frota, ampliar trajetos e horários, mesmo os deficitários, com empréstimo da DSC, e se equiparar ou superar a Condor que, "amaciada" pelo prejuízo, se prepararia para a eliminação. Em 20 anos, a Panair se nacionalizaria. ${ }^{20}$ O governo brasileiro também fora procurado pela $\mathrm{Pan} A m$ e corriam rumores de que a Condor havia feito proposta semelhante, com o pagamento para depois da guerra, e que Vargas teria considerado entregar a administração da empresa ao brigadeiro Eduardo Gomes. ${ }^{21}$ Mas a estratégia da Pan Am não visava à desgermanização. Logo, o Departamento de Estado e a RFC passaram a coordenar as negociaçóes no Brasil, e a Pan Am teve que esperar sinal para entabular conversaçōes. ${ }^{22}$

O esboço do Brazilian National Air Transportation Plan, de William Burden e Frank Russel, foi discutido com Aranha, Salgado Filho e o chefe do Departamento

18 Burden, W. 14/8/1941

19 Caffery, J. 2/4/1941.

20 Burden, W. 14/8/1941.

21 Caffery, J. 5/12/1941.

22 Duggan, L. 23/8/1941. 
de Aeronáutica Civil (DAC), entre outros, em julho de 1941. Ele se fundamentava no desgaste do equipamento, o qual logo deixaria de responder às necessidades do país, e apostava que despertaria o interesse de Vargas por uma nova companhia, operada por brasileiros, com mais de $50 \%$ de capital nacional, que absorvesse as empresas nacionais (isso deixava de fora a Condor) e cujos aviôes fossem de fabricação estadunidense (o que excluía Varig e Vasp ou seu equipamento). Subsídios adicionais ou já existentes seriam transferidos a ela. Para o pagamento da dívida em termos "absolutamente favoráveis", aceitavam-se aeronaves alemãs; garantia-se assistência técnica e operacional e treinamento, e seria sacrificado o controle majoritário das ações da Panair. Mas,

como proprietário de $49 \%$ do estoque de ações da companhia nacional brasileira, o capital norte-americano deteria uma posição muito importante no transporte aéreo local. Mais ainda, eliminada a principal concorrente, a Condor, e incorporados outros potenciais concorrentes, sua posição, daqui a cinco ou dez anos, seria melhor do que se a Panair do Brasil continuasse a ser $100 \%$ norte-americana. ${ }^{23}$

Podia-se, assim, esquivar os nacionalistas, eliminar as concorrentes e o capital alemão e, por fim, retirar os lucros das ações da única empresa de transporte aéreo do país. O viés monopolístico, proibido pela Constituição, só foi apontado como inaceitável pela Panair. Do ponto de vista administrativo, os Estados Unidos lidariam com uma empresa ao invés de quatro, a complexidade do programa seria menor, mais eficiente o uso de equipamento e de pessoal, e mais fácil manter, depois, as influências alemãs fora de uma companhia forte com participação acionária estadunidense. $\mathrm{O}$ aumento na demanda beneficiaria indiretamente a Pan Am no setor internacional. A DSC sustentava que os interesses estadunidenses no setor deveriam ser preservados, tanto quando possível, mesmo pressionando a Pan Am a desistir do controle da Panair. Outra opção era incluir um contrato com a Panair "similar, mas possivelmente menos rígido do que aquele adotado na Bolívia e contemplado na Colômbia, para assegurar adequada e contínua supervisão técnica", acompanhado de acordos para não haver superposição de linhas. ${ }^{24}$

Por parte do Departamento de Estado, subsistia o temor de que a perda de identidade da Vasp, Varig e NAB ferisse o orgulho nacional, o que dificultava a aquiescência do governo com a fusão, apesar de a qualidade administrativa delas ser tão baixa que o dano seria pequeno e a satisfação do governo mais do que compensadora. Por isso, sugeriu que, eventualmente, elas se tornassem subsidiárias nacionais da nova companhia. Vargas não respondia. Os serviços oferecidos pela Condor e ainda os da LATI eram vitais, e tinham que ser mantidos, mas acreditavase que ambas poderiam ficar à mingua de gasolina em dois ou três meses, "até que

23 Burden; W.; Russell, F. 21/7/1941.

24 Burden, W.; Russell, F. 21/7/1941. 
possamos fornecer aviões e equipamentos para capacitar a Pan $A m$ ou uma nova companhia nacional" a cobri-los, sem muita oposição do governo brasileiro. ${ }^{25}$ A Panair pressionava, negando-se a cobrir uma rota deficitária reivindicada pela Condor. A fim de obter sua colaboração, a RFC prometeu os "aviōes necessários, em base de arrendamento, para a duplicação do serviço da Condor". ${ }^{26}$

Em novembro de 1941, sob o sugestivo título "O que a DSC fez e está preparada para fazer para eliminar a Condor”, Barclay Harding, vicepresidente da agência, informava que a $\operatorname{Pan} A m$ exigia sete aviōes para cobrir as rotas da Condor e um para a Rio-Corumbá, inaugurada por incitamento da DSC. Caso o Brasil preferisse transferir o controle da Panair ao governo e a brasileiros natos, estabelecer-se-ia um contrato de longo prazo. Equipamento alemão era aceito para abater a dívida. Por fim, seriam oferecidas 94 bolsas para treinamento de pessoal. ${ }^{27}$ Havia expectativa de que Vargas aprovasse a instalação de uma concorrente. A Pan $A m$ já se dizia disposta a qualquer esforço indispensável para eliminar a Condor, adquirindo os ativos desta em terra e operando seus serviços por cinco anos sem subsídios, e ainda podia surpreender todos, enviando ao Brasil um amigo de Aranha para tentar diminuir seus preconceitos. Ao ser informado pelo Embaixador de que a Condor tinha sido colocada na Lista Negra, Aranha teria replicado: "e a Panair na nossa." ${ }^{28}$ Sabidamente hostil à Panair, mesmo se controlada pelo Brasil, o ministro se opunha enfaticamente a que ela incorporasse a Condor e colocava condições: manter os empregados brasileiros confiáveis, o que solucionava a preocupação com o desemprego de técnicos, e utilizar a Panair apenas temporariamente.

Com a declaração de guerra pelos Estados Unidos, a Pan Am foi proibida de atender passageiros germânicos - entre os quais, supostamente, os espiōes. $\mathrm{O}$ DSC suspeitava da presença de pró-nazistas ou anti-Estados Unidos na cúpula do DAC e no gabinete técnico do Ministério da Aeronáutica, e que o controle da Condor pela Força Aérea Brasileira ocultaria a influência alemã "sob uma máscara brasileira". Por isso, o DSC preferia apostar na cooptação de setores da elite brasileira para a causa estadunidense e atrair empresários, oferecendo financiamento para a compra da Condor. Tirando o governo da jogada, a companhia estaria sob controle e aí, confessa Harding aliviado, "teríamos tempo para reorganizar a firma sob as diretrizes que nos pareçam ser as mais apropriadas". ${ }^{29}$ Mas duvidava que a Alemanha aceitasse negociar. A situação só seria definida rapidamente se Roosevelt autorizasse o corte de combustível. Com efeito, o Departamento de Estado usou esse poderoso recurso, previsto na Lista Negra, para minar as forças da Condor.

25 Caffery, J. 17/9/1941.

26 United States State Department. 20/8/1941.

27 Harding, B. 6/11/1941.

28 American Embassy. War History 1939-1945. Apesar das arestas, o embaixador reconhecia que Aranha trabalhara em benefício dos Estados Unidos.

29 Harding, B. 14/12/1941. 
A Standard Oil já vinha usando de subterfúgios para não atender pedidos. Alegava que não tinha espaço nos tanques do navio, que este já havia deixado o porto, ou que só podia fornecer combustível para menos do que trinta dias. ${ }^{30}$ Para resolver suas urgências, a Condor recorreu ao Exército, de onde a Embaixada identificou um desvio de 300.000 litros, ${ }^{31}$ à International Petroleum e à Standard Oil no Peru e na Bolívia. O comandante da base aérea naval de Florianópolis, tido como simpático aos nazistas, também desviava combustível. ${ }^{32}$ Havia rumores de que setores militares brasileiros com fortes simpatias pela Alemanha, embora não necessariamente pelo nazismo, apoiavam a empresa. A Standard do Brasil foi ameaçada de processo por quebra de contrato. ${ }^{33}$

O secretário de Estado, Cordell Hull, pressionou o Chile, que devia "cessar imediatamente todas as entregas de gasolina e óleo" ao Syndicato Condor, e ordenou sua redução na Argentina. ${ }^{34} \mathrm{Em} 13$ de dezembro, Caffery foi instruído a interromper as vendas de combustível à Condor. Os efeitos foram dramáticos. No mesmo dia, a companhia comunicou ao DAC a suspensão total do tráfego, "a despeito do fato de que tinha em mãos suprimento para três semanas", disse Harding, porque "aparentemente, esperava trazer a público um clamor pela retomada de seus serviços antes que pudéssemos conseguir sua substituição, mas tal clamor não surgiu." 35 A partir daí, chegaram telegramas de informantes de Buenos Aires, Corumbá, Vitória, Manaus, Porto Alegre, Porto Velho, Rio Branco, Natal, Curitiba, S. Paulo e Florianópolis, confirmando a paralisação. Por meio de observadores navais, agentes consulares e da Panair, o adido militar norte-americano mantinha-se a par da movimentação dos aviōes ao longo do litoral, e informava sobre partidas, chegadas, horários, aeronaves e mecânicos nos hangares, e tendências políticas de responsáveis por bases aéreas e aeroportos. ${ }^{36} \mathrm{O}$ Departamento de Guerra do Estados Unidos solicitou que o Brasil colocasse guardas "em todos os depósitos de gasolina, aviões e campos da Condor, especialmente naqueles que apontam em direção à Colômbia, já que, no sudeste colombiano, existem diversos campos de aviação sem supervisão, dos quais os aviōes podem decolar para o Panamá."37

Em resposta às pressões, Aranha, em consulta com Harding, apresentou sua alternativa: fundar uma nova empresa que comprasse o acervo da Condor, com controle acionário de brasileiros sem vínculos prévios com a companhia ou com o governo alemão, mantendo alguns dos diretores nos cargos ou como acionistas

30 Caffery, J. 25/4/1941.

31 The Foreign Service. 5/5/1941.

32 Kazanjian, R. 19/7/1941.

33 Hull, C. 5/6//1941.

34 Hull, C. 8/12/1941.

35 Harding, B. 2/4/1942.

36 Miller, L. 23/12/1941.

37 Caffery, J. 22/12/1941. 
em condição minoritária. A DSC resgataria a dívida com a Lufthansa e teria amplo espaço de manobra, indicando estadunidenses para reorganizar a empresa, treinar pessoal, e garantir a eliminação daqueles que pudessem prejudicar a defesa do hemisfério. No prazo de três a cinco anos, a empresa seria operada exclusivamente por nacionais. Aranha se dispunha a cooperar caso suas sugestões não fossem aprovadas pela Embaixada dos Estados Unidos. ${ }^{38}$

\section{O pessoal indesejado da Condor: germânicos e descendentes}

Durante o tempo em que não havia substitutos disponíveis no Brasil nem nos Estados Unidos, posiçôes-chave na Condor continuavam a ser ocupadas por alemães e brasileiros de origem alemã "com forte simpatia nazista". ${ }^{39}$ A imprensa já noticiara o quão doloroso era "para os que ajudaram a cimentar esta obra, se verem forçados a abandoná-la porque não são brasileiros natos, mormente para os que chegaram a despender 14 anos de cooperação leal e esforçada a serviço da empresa. Felizmente, a maioria compreendeu que era indispensável o sacrifício, e a medida justa e humanitária que assegura a indenização". ${ }^{40}$ No final de 1941, dos 866 alemães da Condor restavam 300, mas 79,1\% dos que recebiam os mais altos salários tinham sobrenomes alemães. ${ }^{41}$ Os interventores dispensaram pessoal dessa origem, alguns especializados e com muito tempo de serviço, o que continuou a ocorrer penosamente, a partir dos cargos mais altos. Caffery alertara Vargas de que as prioridades da DSC podiam dificultar o atendimento aos pedidos de aeronaves, e qualquer demora nas decisôes implicaria em "desvio desse excelente material". ${ }^{42}$ A situação era difícil. A Embaixada desconfiava da lealdade do Ministério das Relações Exteriores, dos interventores e de suas alegações de carência de nacionais habilitados. Numa companhia dessa natureza, quase todas as funções acabavam por ser estratégicas, e a presença de "inimigos" representava riscos, potenciais ou imaginários. Em dezembro, enquanto Muricy desenvolvia seus próprios projetos para reorganizar a Condor, as propostas de Caffery não tinham sido respondidas, e outros planos continuavam igualmente ignorados. ${ }^{43}$ Até janeiro de 1942, a oferta de técnicos estadunidenses e a aprovação de novas rotas da Panair, em troca da aquisição de equipamento vinham sendo rejeitadas. Rotas suspensas estavam por ser retomadas, e em breve as estações de rádio voltariam a funcionar. O problema era o que fazer, daí por diante, com a companhia, que seguia na Lista Negra a

38 Aranha, O. 24/12/1941.

39 Um ano antes, quando a dificuldade já era patente, Vargas autorizara dois alemães naturalizados a pilotarem aviōes da Varig. Caffery manifestou seu desagrado. Adams, W. 1941.

40 Jornal A Noite. "A situação do Sindicato Condor”, 1941.

41 Harding, B. 2/4/1941.

42 Caffery, J. 16/10/1941.

43 Pearl, W. 14-9-1942. 
despeito dos esforços de Muricy. Frente às cobranças das autoridades brasileiras, desejosas de reativar a companhia, mas receosas de que a Panair quisesse assegurar para si o monopólio dos transportes, a embaixada temia que, como próximo passo, o Brasil solicitasse combustível, cuja liberação, "antes da eliminação da perigosa influência alemã”, especialmente de pilotos e operadores de campo de pouso, estava fora de cogitação.

Apesar das considerações do governo brasileiro, simpáticas aos empregados alemães e naturalizados, fosse por razões de cunho social ou por julgar insuficientes as provas da periculosidade dos indicados, o Departamento de Estado só retiraria a companhia da Lista Negra com a exoneração de todos eles. Obter permissão para dispensá-los sem satisfazer seus direitos trabalhistas viabilizou-se por meio de uma reinterpretação da lei de estabilidade: o interesse público. ${ }^{44}$ Um decreto-lei de 31 de agosto 1942 possibilitou a demissão, sem indenização, dos estrangeiros do Eixo não-naturalizados, certificados pela polícia ou por outra evidência documentada como perigosos à segurança nacional ou ao funcionamento adequado da empresa onde trabalhavam. Em alguns casos, não se aplicava aos que vivessem no Brasil há muitos anos, proprietários, com cônjuges ou filhos brasileiros. Em geral, o Ministério do Trabalho autorizava dispensas em empresas que não eram de utilidade pública nem tinham relação com o esforço de guerra, e instituía pequenas indenizações. ${ }^{45}$ Aplicação tão estrita fez com que exonerar trabalhadores qualificados importasse em pesados custos. À espera de solução legal, cogitou-se em afastamento remunerado, ideia rechaçada pelos estadunidenses, que preferiam evitar que lhes sobrasse tempo para atividades subversivas. ${ }^{46}$ Quando quase todo o pessoal germânico foi expurgado, a administração voltou-se aos brasileiros a ele associados.

Proprietários de ações preferenciais da Condor

\begin{tabular}{lccc}
\hline Brasileiros & até 5-3-1940 & no ínterim & após 6-1-1942 \\
\hline Ernesto Pereira Carneiro & 4 & 2 & 2 \\
Ernesto Hoelck & 4 & 4 & 7 \\
George Hern Stoltz & 0 & 3 & 0 \\
Eurico F. Valle & 0 & 2 & 2 \\
José B. Ribeiro Dantas & 0 & 2 & 7 \\
Hern Stoltz \& Cia. & 5 & 0 & 0 \\
José Pires do Rio & 0 & 2 & 2 \\
Alemão & & & 0 \\
Paul Moosmayer & 7 & 5 & \\
\hline
\end{tabular}

Fonte: Pearl, W. 14-9-1942.

44 Caffery, J. 11/2/1942.

45 Daniels. 15/3/1945, p.654.

46 Hardin, T. 18/3/1942. 
As avaliações sobre a confiabilidade das intenções e dos programas de demissão dos interventores oscilavam. Em abril, Francis L. Duncan, enviado pela DSC, já se convencera dos esforços de Muricy e de Bento Ribeiro Dantas, ex-diretor mantido durante a intervenção, "um negociante estabelecido, com considerável conhecimento e ideias práticas sobre o quadro da aviação, no Brasil, e na Condor em particular". Sinceros, agradáveis e cooperativos, "esses cavalheiros são, primeiro, brasileiros leais e, segundo, pró-aliados” e discutiam francamente seus planos e problemas. Portanto, não hesitara em cooperar com eles, esclarecendo-lhes suspeitas que atrasassem a remoção da Lista Negra. Até aquele momento,

mantiveram-me constantemente informado sobre o estado de seu programa de desgermanização e até a data estavam bem adiantados, tendo na última semana dispensado dez alemães que tinham sido agendados para $1^{\circ}$ de julho. Estou convencido de que pretendem eliminar completamente todos os alemães e empregados pró-Eixo e não acredito que seu programa se atrasará, a menos que falhemos em fornecer assistência técnica a tempo para permitir que se complete em julho. ${ }^{47}$

Diante do compromisso das autoridades brasileiras de eliminar todo e qualquer pessoal que fosse apontado como pró-alemão, Hull reafirmou a disposição em cooperar para "assegurar a reorganização bem-sucedida e a operação da Condor como companhia brasileira". Designou a Caffery e Harding a tarefa de indicar "indivíduos específicos cuja remoção faria a atual organização razoavelmente satisfatória”, e que tipo de pessoal estadunidense ou brasileiro seria necessário ou aconselhável para substituí-los. E, para tranqüilizar Vargas, temeroso das intenções monopolistas da Panair, exigiu que a Pan Am suspendesse as rotas que duplicavam as da Condor. Mas instruiu que se evitassem mençōes à liberação de combustível e à retirada da Lista Negra. ${ }^{48} \mathrm{~A}$ tática era criar empecilhos ao seu reconhecimento como empresa brasileira confiável, bloqueando-a sob a alegação de que era vital para a espionagem e atividades de propaganda inimiga.

Tentando abrandar os entraves colocados pelo Brasil, a DSC se dispunha a aceitar os avióes alemães e a passar à Condor os novos, que tinham sido entregues à Panair. O DAC rejeitou. ${ }^{49}$ Dado que os serviços de inteligência estadunidenses asseguravam que os alemães pretendiam voar de Dacar a Natal, ${ }^{50}$ o controle do espaço aéreo entre a África e a América era um recurso de poder. No clima de pressōes, o adido naval estadunidense declarou ser indesejável, no nordeste, a operação de um aparelho da Condor que, por ser muito semelhante aos aviōes

47 Duncan, F. 22/4/1942.

48 Hull, C. 4/2/1942, 11 p. m., p.768.

49 Harding, B. 14/2/1942.

50 Berle Jr., A. 8/4/1941. 
de guerra alemães, poderia confundir e permitir que estes aterrissassem nas bases navais sem serem incomodados..$^{51}$ Ninguém deixava de observar.

Com os estatutos refeitos, as ações e a administração em mãos de brasileiros natos, Muricy pediu ao ministro da Aeronáutica para reiniciar os serviços. Voos e deslocamentos de aeronaves para conserto foram autorizados por ele perante a apresentação de uma lista dos funcionários da companhia com suas respectivas nacionalidades. ${ }^{52}$ Numa reunião em Washington com o Departamento de Estado e a DSC, o embaixador do Brasil, Carlos Martins, e o ministro das Finanças, Arthur de Souza Costa, precisaram oferecer novas garantias de desgermanização da Condor para obter materiais de defesa para o Brasil. ${ }^{53}$ Mas o Departamento de Estado insistia em sua alta periculosidade. Havia a opção de o Brasil aceitar que a Panair, que já tinha mais de $90 \%$ do serviço da Condor, continuasse a postos, mas os estadunidenses eram conscientes dos sentimentos contra a Panair, que tampouco tinha desempenho satisfatório. Os Estados Unidos ofereciam consultores para reorganizar a Condor, aviōes novos, com os quais o pessoal de voo não estava familiarizado, e treinamento para formar mecânicos em sete meses, pilotos em oito, supervisores mecânicos em 20, e engenheiros aeronáuticos de alta classe em dois anos. Era serviço completo. Assim, "gradualmente, sob a supervisão dos consultores civis estadunidenses, os novos equipamentos podem ser introduzidos" até a substituição total. ${ }^{54}$ Para pressionar o DAC, o argumento era que, "se os serviços de substituição da Panair permanecessem, a Condor não poderia funcionar com sucesso, a menos que o governo brasileiro quisesse pagar um grande subsídio para operar aviōes vazios." 55 Um mês depois, consideravase a hipótese de propor a retirada da empresa da Lista Negra como prêmio pela execução do plano, e notificar a Panair a deixar as rotas da Condor. ${ }^{56}$

Após dias de reuniões, estimativas de custos de operação e de equipamento, e visitas à base da Condor, Duncan, Dantas e Muricy revisaram planos e problemas. Dantas pediu então a Aranha três aeronaves e assistência técnica estadunidenses, e avisou a Lufthansa da transferência do débito para o governo. A pressão exercida pela Lista Negra era, no entanto, insuportável, e havia grande ansiedade em solucioná-la de modo a obter combustível, equipamento para manutenção e vistoria dos novos aviōes, e os assistentes técnicos indicados por Duncan. Para este, aviôes e empregados habilitados nas técnicas e métodos usados pelas empresas domésticas nos Estados Unidos assegurariam o salto da Condor para tornar-se economicamente segura e eventualmente uma das melhores empresas na América

51 Brady Jr., E. 1942.

52 Caffery, J. 6/2/1942, 4 p. m., p.771.

53 Hull, C. 13/2/1942, 11 p. m., p.771.

54 Duggan, L. 9/2/1942.

55 Harding, B. 14/2/1942.

56 Hardin, T. 18/3/1942. 
do Sul, comparável às mais modernas no mundo. O pedido de três avióes seria apenas o primeiro, seguido por quantidades crescentes. Logo que a empresa saísse da Lista Negra, ele pretendia retornar a Washington para providenciar peças e técnicos, levando consigo Dantas e pessoal para treinamento.

Hull procurou aproveitar a solicitação de gasolina e os recuos de Vargas para impor condições, como a eliminação de operadores de rádio e de um diretor "alemão", Ernesto Hoelen ou talvez Hoelik, Holck, Hölck ou Hoelck, dizia, e a desvinculação com a antiga empresa, deixando a Caffery decidir a desejada mudança do nome, "a fim de dar ênfase ao fato de que ela foi reorganizada como uma companhia nacional brasileira". ${ }^{57}$ A reforma do contrato social cancelou o poder de Hoelck; suas ações passariam a brasileiros aprovados por Aranha. ${ }^{58}$ Tom Hardin, técnico em aviação da DSC, foi enviado ao Rio para indicar que empregados demitir, e pessoal temporário dos Estados Unidos para treinar brasileiros satisfatórios para as vacâncias. A operação não havia terminado, mas a Embaixada aconselhava prudência. Qualquer reorganização da Condor sob direção estadunidense não parecia possível ou desejável. Novas pressões sobre o Brasil soariam como impertinência. Deixada por conta própria, a companhia continuaria a se desintegrar; se expropriada, os Estados Unidos correriam o risco de perder o controle garantido pelas restriçóes à venda de gasolina, mas estas se tornavam constrangedoras se o pedido viesse do governo Vargas, que se tornaria concorrente da Panair. Em suma, "o mais desafortunado desenrolar para o transporte aéreo internacional norte-americano, o qual provou ser um elemento importante no comércio interamericano e na defesa do hemisfério". 59

Nesse ínterim, Muricy e Dantas sugeriram o confisco do débito da Condor para repor a perda dos navios brasileiros bombardeados. Vargas demonstrou simpatia pela ideia. ${ }^{60} \mathrm{Em}$ março de 1942 , os bens da Lufthansa foram transferidos à Condor, e, pelos decretos-lei 4166 e 4174, pessoas jurídicas organizadas segundo a lei brasileira passaram a interventores militares, o que incluía a grande massa das aplicações alemãs. A Embaixada acusou esses interventores de trabalharem para a Alemanha e de promoverem os fins de tais empresas, como meros subalternos. Para acalmar os ânimos, Aranha declarou que a oportunidade de transformar a Condor em uma companhia genuinamente brasileira fora um dos raros benefícios trazidos pela guerra. Duncan era de opinião que o Brasil pretendia assumir o débito para mantê-la em operação, expandindo-se como empresa nacional. ${ }^{61}$ Em abril, o governo auditava os débitos com a Lufthansa. A posição do caixa da Condor parecia ruim: devia à Alemanha mais do que o dobro de seu ativo, mas,

57 Hull, C. 5/2/1942, 11 p. m., p.769.

58 Serviços Aéreos Condor. 19/12/1942.

59 Caffery, J. 11/2/1942.

60 Hardin, T.; Harding, B. 5/3/1942.

61 Duncan, F. 22/4/1942. 
analisava um funcionário júnior da embaixada, aquela não era "uma questão séria porque, se ganharmos a guerra, os interesses alemães serão adequadamente cuidados e, se perdermos, a Alemanha se apropriará do Brasil de qualquer maneira." Preocupante era a frouxidão do governo em eliminar os investimentos alemães, facilmente solucionável por um decreto-lei, ou a falta de informação a respeito dos empregados indesejáveis. ${ }^{62}$

Harding participou em três reunióes: uma com Eduardo Gomes, outra com Junqueira Alves, novo diretor da DAC, e por fim com Muricy. Embora a Condor estivesse sendo administrada por brasileiros, esses eram apontados como "agentes e empregados do governo alemão e pró-Alemanha em suas simpatias". A filiação ideológica era uma alegação sempre pronta a ser esgrimida. Questionado a respeito, Eduardo Gomes admitiu o fato, mas argumentou que "o povo tem permissão para ter quaisquer ideias que deseje, desde que não estejam contra os interesses do país". ${ }^{63}$ Segundo o adido naval norte-americano, Gomes chegara a Recife pela Condor, pouco antes, em companhia de um oficial alemão. Tal atitude, coerente com as declaraçóes democráticas do brigadeiro, deixava os agentes do Departamento de Estado assustados.

Harding não acreditava no empenho de Vargas em tornar a Condor uma empresa nacional, tendo sido recorrentemente recusadas as ofertas da DSC. Contudo, Muricy lhe expusera seu enorme desejo de livrar a empresa da Lista Negra, tendo declarado que "muitos dos brasileiros na companhia, que tinham antes expressado sentimentos pró-germânicos porque queriam ficar bem com os empregados alemães, agora expressavam diferentes opiniōes”. E, apesar de haver muitos simpáticos aos alemães, eles eram brasileiros, e não agiriam contra os interesses do país. Ele se ressentia da imposição de pessoal e equipamento e queixava-se da Panair, que teria desenvolvido um plano sagaz para estabelecer um monopólio no Brasil e tirar vantagem durante esse período difícil. ${ }^{64}$ Certo de que Muricy não se decidia entre alemães e estadunidenses, Harding sugeriu ao DAC que indicasse "um homem ou um comitê experiente em negócios e aviação para analisar o transporte aéreo brasileiro e formular um plano para seu desenvolvimento." O baixo prestígio de Muricy junto ao Departamento de Estado podia piorar com a opinião de que tanto ele como Dantas eram

completamente incompetentes enquanto homens de negócios e executivos, e incapazes de dirigir as operações de uma linha aérea em boas condiçōes... ambos são conscientes de suas deficiências e sua insistência na manutenção de Hoelck tem como o propósito manter alguém mais na base, capaz de executar os deveres que eles ostensivamente estão assumindo. ${ }^{65}$

62 White. 28/7/1942.

63 Harding, B. 14/2/1942.

64 Harding, B. 14/2/1942.

65 Hardin, T. 18/3/1942. 
Em maio, técnicos alemães e naturalizados seguiam em posições estratégicas. O tempo era insuficiente para que eles capacitassem os brasileiros, mas bastante para insinuarem ideias germânicas. Antigos sócios continuavam como diretores ou tinham indicado os novos. Aparentemente, apenas Muricy não tinha conexões com eles, mas as dúvidas sobre sua competência não tinham sido afastadas. Malentendidos e discordâncias sobre os riscos de subversão interna vinham ocupando tempo que os interventores podiam dedicar a um programa de introdução de equipamento e assistência técnica norteamericana. Duncan advertia que o trabalho dos estadunidenses não seria apenas o de ensinar a operar aviōes, técnicas de vistoria e manutenção, mas "eliminar a influência alemã e instilar ideias americanas", 66 e somente com a instalação de pessoal leal em posições-chave se confirmaria ou não a existência de atividades subversivas. Defendia a infiltração.

Para tentar acabar com a história que se arrastava e com as perdas sofridas pela Condor, que já vinham irritando Vargas, Aranha solicitou à embaixada que enviasse alguém para instruir o que fazer: "a designação de um técnico de sua confiança para certificar-se de que a Condor é uma empresa brasileira e só age de acordo com os interesses do Brasil". Ao mesmo tempo, mandou um recado para a Panair, ao dizer que o governo pretendia "evitar a existência no Brasil de um monopólio aéreo, real ou disfarçado". ${ }^{67}$ A situação era tão obscura que, em agosto, os jornais do Rio estamparam um anúncio pago: "A Condor é brasileira... desejamos chamar a atenção do povo desta capital, nessa grave hora de nossa vida nacional, quando ele está expressando sua indignação diante da brutalidade do totalitarismo, de que não deve agir sem primeiro se assegurar contra quem está." 68 O objetivo era protegê-la dos quebra-quebras contra as propriedades alemãs que se seguiram ao bombardeio de barcos brasileiros.

\section{O início da era DC3}

A Condor havia reassumido, em princípios de 1942, a rota Porto Velho-Rio Branco, usando o antigo hidroavião alemão de quatro passageiros, cujos voos semanais coincidiam com os da Panair. ${ }^{69}$ Muricy rejeitara o equipamento e a assistência técnica estadunidense já que o ressentimento provocado nos orgulhosos alemães e pró-alemães por esse tipo de ingerência tornaria impossível à companhia operar. Mas Hardin assegurava que os aparelhos alemães praticamente não tinham valor como meio de transporte rápido. De início desconfiados, os interventores foram sendo convencidos. Após conversas com o ministro da Aeronáutica, optou-se, em março, por um DC3. O DSC esperava uma encomenda inicial de não mais que

66 Duncan, F. 6/5/1942.

67 Aranha, O. 30/7/1942.

68 Simmons, J. 19/8/1942.

69 Hart, P. 14/2/1942. 
cinco unidades, cujo atendimento justificaria um certo "sacrifício", mas colocaria "automática e simultaneamente o pessoal de operação estadunidense dentro da organização”. Eventualmente a reposição chegaria a $100 \% .^{70}$

Conquistados pelas "marcantes vantagens econômicas do DC3" que, embora mais caro, era de operação mais econômica e poderia garantir um lucro de US $\$ 0,35$ por milha, enquanto os JU52 provocavam uma perda de US $\$ 0,31,{ }^{71}$ ficava difícil a Dantas e a Muricy insistirem nas máquinas alemãs, e eles decidiram solicitar os aviōes e a assistência. Os serviços de inteligência estadunidenses viam perspectivas. As relaçóes comerciais com a Condor manteriam a necessidade de assistência por um período considerável e o governo dos Estados Unidos "acuradamente informado". E tudo seria coroado pela amizade continental. Duncan recomendou presteza e "uma atitude muito liberal referente aos aspectos econômicos da transação". Tornando-se a Condor economicamente viável, tomava-se o lugar do capital alemão.

Mas o Departamento de Estado se dizia descontente até que a influência alemã fosse "satisfatoriamente eliminada". Para uma empresa que dependia de equipamentos e combustíveis importados, a inclusão na Lista Negra era fatal, e a demanda dos interventores era livrá-la do empecilho. O episódio se caracterizava por oscilações e posturas obstinadas por parte dos Estados Unidos. Ora se dizia que as garantias eram insuficientes, ora que a administração não cumpria as metas. A exclusão da Lista funcionaria "como atestado de saúde". Aumentava o rol dos funcionários cuja dispensa era exigida, com justificativas imprecisas para alguns e sem acordo entre os governos em relação a outros. Em abril de 1942, Harding confessou que não estava seguro do fim da influência alemã na Condor ou de sua utilização para espionagem, e o mesmo sentiam Hardin e Caffery. Contudo, mantê-la na Lista Negra tinha sido uma das mais constantes fontes de fricção, e os danos talvez ultrapassassem qualquer proveito obtido. Portanto, aconselhava a contraespionagem. Se isso possibilitasse descobrir atividades do Eixo na Condor, a ação direta do Brasil seria uma resposta mais imediata e permanente do que o controle estadunidense, necessariamente remoto. ${ }^{72}$ Mas havia condições: de que a companhia se tornasse uma sociedade anônima com ações nominativas, que sua diretoria fosse composta sem interferência da administração anterior e por brasileiros natos confiáveis, excluindo Dantas e Hoelck, "que sempre participaram da administração antiga da Condor, radicados nos seus hábitos e sistema antes do advento da guerra, apesar de serem ambos brasileiros natos". ${ }^{73}$

Muricy e Dantas solicitaram a ajuda de Aranha, acenando com a intenção de contratar Duncan, cuja permanência como conselheiro técnico foi pedida até que

70 Harding, B. 7/4/1942.

71 Duncan, F. 11/4/1942.

72 Harding, B. 2/4/1942.

73 Hardin, T. 7/4/1942. 
se concluísse o caso. A conveniência de adquirir três aviões obrigava a concessões, e o poder dos Estados Unidos continuava a ser maior. A retirada da Lista Negra não se concretizava, sob reiteradas alegações de que o Brasil não havia cumprido integralmente sua parte. ${ }^{74}$ Em setembro, a DSC fez uma avaliação negativa dos novos sócios e de suas lealdades à causa aliada, e da ingerência da Lufthansa (que permanecia como credora), e considerou confusa a estrutura organizacional e financeira da Condor. Mas "preparou-se para adquirir alguns aviōes para uso da Condor, junto com o equipamento necessário e o pessoal técnico. No entanto, em vista do atraso e da pressão de outras necessidades de guerra, esses avióes e equipamentos tiveram que ser usados em outro lugar e o pessoal não pôde ser mantido." 75

Já se ouviam, então, vozes favoráveis à exclusão da Condor da Lista Negra. Um funcionário da Embaixada argumentou que seu bloqueio não era de vital importância para o programa, e fricçôes diplomáticas poderiam obrigar à sua retirada, dando mostra da fragilidade dos Estados Unidos, como no caso da Brahma, "tão nazi agora como era há um ano atrás, e cuja retirada da Lista Negra sem dúvida afetou adversamente o prestígio da embaixada" ${ }^{76}$ Os motivos de preocupação deveriam ser, segundo ele, a tendência da Alemanha a burlar planos e manobras estadunidenses e proteger seus investimentos, e o risco que a embaixada corria de ter que dividir o direito de controlar a Lista Negra "com qualquer um". Por outro lado, a simpatia de oficiais do Exército e de importantes civis pelos nazistas permitira a proteção de aplicações econômicas e financeiras do Eixo, deixando os Estados Unidos em posição desvantajosa, o que, na conjuntura de guerra, poderia adquirir tons funestos.

Sendo a situação complicada por tantas circunstâncias e tão estritamente relacionada aos esforços de guerra, a retirada da Condor da Lista Negra não podia servir de precedente para outros casos. ${ }^{77}$ Como parte do programa de solidariedade hemisférica, a pretensão dos Estados Unidos de instalar seus equipamentos em lugar dos alemães afigurava-se "a melhor proteção contra os interesses ou o controle alemães depois da guerra", ao representante da DSC, Alexander Royce, que recomendou o envio, logo após a remoção da Condor da Lista, de técnicos com um DC3, do tipo exclusivo do exército dos Estados Unidos, "para ajudar a companhia na preparação de sua organização para o efetivo uso do equipamento norte-americano." 78 Haveria que garantir que a empresa manteria a Embaixada informada de mudanças no pessoal, e pronta para remover qualquer empregado

74 Caffery, J. 21/4/1942.

75 Pearl, W. 14/9/1942.

76 White. 28/7/1942.

77 Royce, A. 29/10/1942.

78 Royce, A. 30/10/1942. 
apontado como pró-Eixo ou inimigo da causa aliada. ${ }^{79}$ Mas o que asseguraria a boa conduta da Condor seria a presença de técnicos estadunidenses e do próprio Duncan, que apostava na colaboração de Dantas e Muricy. ${ }^{80}$ Por fim, era preciso aliviar a situação delicada com o governo brasileiro.

\section{Conclusões}

Nenhum dos planos de desgermanização chegou a bom termo enquanto a Condor esteve em condições de apelar a simpatizantes em posições no governo. $\mathrm{O}$ próprio Exército interferira na proibição de venda de gasolina, embora o bloqueio promovido pela Lista Negra gerasse penosas restriçōes. A concorrência da Panair também ajudou a enfraquecer a empresa, já debilitada pelas carências e pelo uso de equipamento defasado. Mas a DSC teve de introduzir reparos no projeto de criar uma nova companhia que viesse operar somente com equipamento fabricado nos Estados Unidos. Foi preciso fazer concessōes importantes ao Brasil em outras questôes, e o Embaixador desaconselhou o uso de pressão política e econômica para obter a cooperação de Vargas. ${ }^{81}$

Apesar do esforço brasileiro em prol do reconhecimento da nacionalização da empresa, o efeito simbólico do nome Condor, estimado de grande valor e reputação pelo Brasil, era forte o suficiente para que Departamento de Estado o considerasse inaceitável, embora, no começo das negociações, dissesse que tal mudança só seria solicitada se absolutamente necessária. ${ }^{82}$ Mas a pressão persistiu e, em outubro, a empresa cedeu. Uma nova denominação lhe foi atribuída ao ser retirada da Lista Negra e considerada reorganizada: Serviços Aéreos Cruzeiro do Sul. Sai o símbolo andino e entra o da bandeira brasileira. Isso representou um ônus para seus cofres esgotados, e esperava como compensação "os serviços que o governo americano pretende contratar no programa de desenvolvimento da borracha, conforme declarações que nos têm sido feitas na Embaixada". 83

Solucionados os principais impasses, dentre os quais a demissão de alguns alemães que haviam continuado na empresa, o secretário de Estado despachou quatro técnicos, com as despesas pagas por um ano ao menos, para auxiliar no uso de equipamento e métodos de operaçãao, ${ }^{84}$ e a DSC enviou, sem ônus, Duncan e

79 Royce, A. 14/10/1942.

80 Duncan, F. 21/10/1942.

81 Pearl, W. 14/9/1942.

82 Hardin, T.; Harding, B. 5/3/1942.

83 Serviços Aéreos Condor 19-10-1942. Estando a empresa na Lista Negra, era proibido que uma agência norte-americana, como a U.S. Purchasing Commission, fretasse Junkers da Condor para o transporte de borracha e materiais estratégicos na Amazônia.

84 Hull, C. 29/12/1942. 
um DC3, com expectativa de negociar mais aeronaves que ficassem disponíveis. ${ }^{85}$ $\mathrm{Na}$ área de public relations, foi necessário melhorar o entendimento entre as autoridades brasileiras e a Panair, sobre a qual pairavam suspeitas, e mesmo a acusação de tentar "roubar todos os pilotos da Condor", oferecendo-lhes melhores salários, ${ }^{86}$ apesar do "grande trabalho missionário da Embaixada para corrigir a situação". ${ }^{87} \mathrm{O}$ reatamento deu-se com uma visita do vice-presidente da Pan Am à Cruzeiro, seguida de conversas entre as diretorias. Passou-se a aplicar o princípio da intensificação da cooperação para extinguir as atitudes belicosas, "com o fim de melhor servir o país". ${ }^{88}$ A Cruzeiro autorizou a prestação de auxílio técnico e material à Pan Am e à Panair, em qualquer emergência. O mesmo fez a Panair. ${ }^{89}$ Estabeleceu-se a paz. Tempos depois, a Cruzeiro voaria novamente sobre os Andes, e a Panair passaria docemente à memória nacional.

\section{Fontes primárias}

\section{Confidential Files - Record Group 84:}

American Embassy. War History 1939-1945, v. IV-EC.

Mattix, P. 28-1-1941, v. IX E-C

White. 28-7-1942, v. V-EC

\section{Strictly Confidential Files - Record Group 84:}

Aranha, Oswaldo. 30-7-1942

Committee of the House of Representatives, 16-10-1941

Donnelly, Walter. 31-10-1941

Summary Report on Air Activity in Brazil and South America, 1941, p. 5

United States State Department. 20-8-1941

United States State Department. 30-7-1940

\section{Record Group 84:}

27-3-1941, v. XXXVIII

Adams, W. 8-3-1941, v. XXXVII

Aranha, Oswaldo. 24-12-1941, v. XXXVII

Berle Jr., Adolf. 8-4-1941, v. XLVIII

Brady Jr., E. E. 1942, v. L

Burden, William. 14-8-1941, v. XXXVIII

Burden, William; Russell, Frank. 21-7-1941 v. XXXVIII

Caffery, Jefferson. 11-2-1942, v. XLVIII

Caffery, Jefferson. 16-10-1941, v. XXXVII

85 Caffery, J. 7/12/1942.

86 TAX. 4/5/1942.

87 Caffery, J. 19/12/1942.

88 Serviços Aéreos Cruzeiro do Sul. Circular 1942.

89 Panair do Brasil. 10/12/1942. 
Caffery, Jefferson. 17-9-1941, v. XXXVII

Caffery, Jefferson. 19-12-1942, v. L

Caffery, Jefferson. 21-4-1942, v. L

Caffery, Jefferson. 22-12-1941, v. XXXVII

Caffery, Jefferson. 2-4-1941, v. XXXVII

Caffery, Jefferson. 25-4-1941, v. XXXVII

Caffery, Jefferson. 5-12-1941, v. XXXVII

Caffery, Jefferson. 5-12-1941, v. XXXVII

Caffery, Jefferson. 7-12-1942, v. L

Duggan, Laurence. 23-8-1941, v. XXXVIII

Duggan, Laurence. 9-2-1942, v. XLVIII

Duncan, Francis. 11-4-1942, v. L

Duncan, Francis. 21-10-1942, v. L

Duncan, Francis. 22-4-1942, v. XLVIII

Duncan, Francis. 6-5-1942 v. L

E. O’S [O'Shaughneny] 12-8-1941, v. XXXVII

Hardin, Thomas. 18-3-1942, v. XLVIII

Hardin, Thomas. 7-4-1942, v. L

Hardin, Thomas; Harding, Barclay. 5-3-1942, v. XLVIII

Harding, Barclay. 11-2-1942, v. XLVIII

Harding, Barclay. 14-12-1941, v. XXXVIII.

Harding, Barclay. 19-12-1941, v. XXXVII

Harding, Barclay. 2-4-1942, v. L

Harding, Barclay. 6-11-1941, v. XXXVIII

Harding, Barclay. 7-4-1942, v. L

Hart, Parker. 14-2-1942 v. XLVII

Hull, Cordell. 29-12-1942, v. L

Hull, Cordell. 5-6-1941, v. XXXVII

Hull, Cordell. 8-12-1941, v. XXXVII

Jornal A Noite. "A situação do Sindicato Condor", 6-2-1941, v. XLVIII

Kazanjian, Reginald. 19-7-1941, v. XXXVII

Miller, Lehman. 23-12-1941 v. XXXVII

Panair do Brasil. 10-12-1942, v. L

Pearl, W. Hugh. 14-9-1942, v. L

Royce, Alexander. 14-10-1942, v. L

Royce, Alexander. 29-10-1942, v. L

Royce, Alexander. 30-10-1942, v. L

Serviços Aéreos Condor. 19-12-1942, v. L

Serviços Aéreos Cruzeiro do Sul. Circular 1942, v. L

Simmons, J. 19-8-1942, v. L

TAX [Xanthaky, Theodore]. 23-4-1941, v. XXXVII

TAX [Xanthaky, Theodore]. 4-5-1942, v. L

THE FOREIGN SERVICE. 5-5-1941, v. XXXVII

\section{Fontes secundárias}

Caffery, Jefferson. 6-2-1942, 4 p. m., In: U. S. Government. Foreign Relations of the U.S., 1942, Washington: Government Printing Office, v. V, p.771.

Daniels (Chargé d'Affaires). 15-3-1945, In: U. S. Government. Foreign Relations of the U.S., 1945. Washington: Government Printing Office, v. IX, p.654. 
Hull, Cordell. 13-2-1942, 11 p. m., In: U. S. Government. Foreign Relations of the U.S., 1942, Washington: Government Printing Office, v. V, p.771.

Hull, Cordell. 4-2-1942, 11 p. m., In: U. S. Government. Foreign Relations of the U.S., 1942, Washington: Government Printing Office, v. V, p.768.

Hull, Cordell. 5-2-1942, 11 p. m., In: U. S. Government. Foreign Relations of the U.S., 1942, Washington: Government Printing Office, v. V, p.769.

QUINTANEIRO, Tania. Dilemas da cooperação: conflitos gerados pela política das "Listas Negras” no Brasil durante a Segunda Guerra Mundial. Rev. bras. polít. int., Brasília, v. 49, n. 2, Dec. 2006. Available from <http://www.scielo.br/scielo.php? script=sci_arttext\&pid=S0034$73292006000200005 \& \operatorname{lng}=$ en $\& \mathrm{nrm}=\mathrm{iso}>$. access on 06 december 2008. doi: 10.1590/ S0034-73292006000200005.

QUINTANEIRO, Tania. A LATI e o projeto estadunidense de controle do mercado de aviação no Brasil. Varia História., Belo Horizonte, v. 23, n. 37, June 2007. Available from < http://www.scielo. $\mathrm{br} /$ scielo.php? script $=$ sci_arttext\&pid $=$ S0104-87752007000100013\&lng $=$ en $\& \mathrm{nrm}=\mathrm{iso}>$. access on 06 december 2008. doi: 10.1590/S0104-87752007000100013.

Recebido em 27 de agosto de 2008 Aprovado em 20 de fevereiro 2009

\section{Resumo}

Análise e avaliação da política dos Estados Unidos de extinção das atividades da empresa de transporte aéreo Condor, por meio de sua inclusão na Lista Negra, do corte no fornecimento de combustível, da pressão pela exclusão de trabalhadores e acionistas alemães ou simpatizantes do Eixo. Consideraram-se outros meios, como a oferta de crédito para aquisição de equipamentos de aviação estadunidenses e de ações da Condor, e treinamento de brasileiros, assim como infiltração de técnicos e consultores na empresa.

\section{Abstract}

Analysis and evaluation of U.S.A. policy to extinguish activities of Condor's air transportation, by placing it on the Proclaimed List, cutting the supply of aviation fuel, exerting pressure for the displacement of German workers and shareholders or sympathizers of Axis countries. Other means such as the offer of credits for the acquisition of aviation equipments and Condor shares, the training of Brazilian substitutes, as well as the infiltration of technicians and consultants inside the company are also considered.

Palavras-chave: Condor; Segunda Guerra Mundial; Estados Unidos; Brasil Key words: Condor; World War II; United States of America; Brazil 